\title{
PRÁTICA DOCENTE NO ENSINO DE GEOGRAFIA: REFLEXÕES A PARTIR DE ESCOLAS ESTADUAIS PARAIBANAS
}

\author{
Teaching practice in geography education: reflections from state parish schools
}

\author{
Eduardo Barboza de Souza* \\ Thais Mara Souza Pereira** \\ Erimágna de Morais Rodrigues ${ }^{* * *}$
}

*Universidade Federal da Paraíba - eduardosouza369@hotmail.com. **Universidade Federal do Pernambuco - thaismara_estrela@hotmail.com.

***Universidade Estadual da Paraíba - erimagnarodrigues@gmail.com.

Recebido em 01/08/2018. Aceito para publicação em 20/08/2018.

Versão online publicada em 03/09/2018 (http://seer.ufrgs.br/paraonde)

\begin{abstract}
Resumo:
Sabe-se que os estudos voltados à prática docente têm se intensificado bastante na contemporaneidade, com base em estudos diversos na área percebemos a necessidade de uma maior discussão e reflexão acerca de tal. Nessa perspectiva, objetivamos com essa pesquisa refletir a prática de ensino em Geografia dos professores da rede estadual de ensino no município de Itabaiana-PB. Para a efetivação, utilizamos os seguintes procedimentos metodológicos: a) levantamento bibliográfico e documental, b) planejamento da pesquisa, c) observação participante, d) coleta de informações por meio de questionários e e) análise dos dados obtidos. Com base nas reflexões realizadas, mesmo sabendo das grandes dificuldades que permeiam o ensino público, percebemos a necessidade de uma maior reflexão por parte dos professores sobre sua própria prática, de modo que, só assim possa emergir possibilidades de intervenção.
\end{abstract}

Palavras-chave:Prática docente, ensino de geografia, escola pública.

\begin{abstract}
:
It is known that the studies directed to the teaching practice have intensified a lot in the present time. Based on diverse studies in the area we perceive the necessity of a greater discussion and reflection about this issue. From this perspective, we aim with this research to reflect the teaching practice in Geography of the teachers of the public education network in the city of Itabaiana-PB. To this end be effective, we used the following methodological procedures: a) bibliographical and documentary survey, b) research planning, c) participant observation, d) information collection through questionnaires, and e) analysis of the data obtained. Based on the reflections made, even knowing the great difficulties that permeate public education, we perceive the need for a greater reflection on the part of the teachers about their own practice, so that only in this way can possibilities of intervention emerge.
\end{abstract}

Key-words:Teaching practice, geography teaching, public school.

\section{Introdução}

Em uma perspectiva escolar, analisamos que diante das mudanças de ordem econômica e social, a escola não se encaixa com os métodos tradicionais, entretanto, as mudanças necessárias à escola atual depende de fatores e métodos diversos. Diante deste contexto, pretendemos então desenvolver uma análise cujo tema aborda a metodologia do ensino de Geografia, desta forma, problematizando 
as práticas docentes nas escolas estaduais do município de Itabaiana - PB. Com a referida pesquisa objetivamos refletir a prática de ensino em Geografia dos professores da rede estadual de ensino no município em estudo.

Tomamos como base as atividades como docente em escolas da rede estadual, assim possibilitando um contato diário com profissionais da educação, onde, diante da prática de alguns deles, gerou certa inquietação em analisar de maneira efetiva as práticas de ensino desses professores através do contato com as aulas ministradas.

Para a efetivação dessa pesquisa utilizamos a abordagem qualitativa. Num primeiro momento foi realizado um levantamento bibliográfico. Logo após foi realizado um levantamento documental, este, na 12 ${ }^{a}$ Gerência Regional de Ensino, e também, nas bibliotecas e secretarias das referidas escolas.

Em um processo contínuo, para a efetivação da pesquisa, tomamos por base alguns procedimentos metodológicos, a saber: a) levantamento de fontes referentes ao tema da pesquisa, b) planejamento da pesquisa, c) observação participante, d) coleta de informações por meio de questionários, e) análise dos dados obtidos. A partir do uso destas ferramentas metodológicas esperamos compreender parte da complexidade do processo ensino-aprendizagem desenvolvida em sala de aula, na relação efetiva entre professor e aluno. Tais procedimentos foram aplicados nas escolas estaduais do município de Itabaiana - PB são elas: Escola Estadual de Ensino Fundamental João Fagundes de Oliveira e na Escola Estadual de Ensino Médio Inovador Dr.․ Antônio Batista Santiago.

\section{A Prática Docente e seus reflexos no cotidiano}

Pensando a prática docente no ensino de Geografia, Cavalcanti (2003) diz que pensar esse ensino, os saberes e práticas dos professores, com base nas mudanças ocorridas na dinâmica da sociedade contemporânea, de fato, é um elemento importante, pois o ensino, a educação são expressões da sociedade, da economia, da política, da cultura, enfim, de todo esse conjunto (CAVALCANTI, 2003).

De acordo com as ideias de Tardif (2014) a prática docente não é resultado apenas do saber oriundo das ciências sociais. Ela mobiliza outros saberes chamados pedagógicos que incorporados à prática e à atuação docente, fornecem arcabouço ideológico, algumas formas de saber-fazer e algumas técnicas. Esses saberes precedem e dominam a prática docente, mas não provêm dela. Eles se "apresentam como doutrinas ou concepções provenientes de reflexões sobre a prática educativa no sentido amplo do termo, reflexões racionais e normativas que conduzem a sistemas mais ou menos coerentes de representação e de orientação da atividade educativa" (TARDIF, 2014, p. 37).

Sabemos que a teoria deve está sempre associada à prática, para só assim haver uma efetivação da atividade docente. Nessa perspectiva, Tardif (2014) aponta que:

Se assumirmos o postulado de que os professores são atores competentes, sujeitos ativos, deveremos admitir que a prática deles não é somente um espaço de aplicação de saberes provenientes da teoria, mas também um espaço de produção de saberes específicos oriundos dessa mesma prática. Noutras palavras, o trabalho dos professores de profissão deve ser considerado como um espaço prático específico de produção, de transformação e de mobilização de saberes, e, portanto, de teorias, de conhecimentos e de saber fazer específicos ao ofício de professor (TARDIF, 2014, p.234).

Com base nas ideias de Tardif (2014), do ponto de vista tipológico, podemos identificar/classificar os saberes docentes em quatro categorias, a saber: a) saberes da formação profissional, b) saberes disciplinares, c) saberes curriculares e d) saberes experienciais ou práticos.

Assim como os saberes docentes, a prática docente é um elemento fundamental de análise da 
formação e ação do professor. Nessa perspectiva, Bento (2009) recorre às contribuições de Perrenoud (1993), ao afirmar que em muitas situações a ação do professor não é a concretização da teoria, não é uma representação consciente do que é pertinente fazer em diferentes situações, até por que o professor não é provido de receitas na memória que ditem o que ele deve fazer no momento desejado. Essa ausência de "receitas" muitas vezes acontece quando o professor se encontra numa situação nova ou muito habitual, que pode ser resolvida sem nenhuma regra. Entretanto, a ação pedagógica, mesmo tendo um caráter improvisador, não permite que o professor chegue à sala de aula sem preparação (PERRENOUD apud BENTO, 2009).

Deste modo, um dos pilares do trabalho do professor é a prática, afinal o docente está em ação durante quase todo o seu dia, pelo menos enquanto está ministrando suas aulas ou as preparando. Essa é uma das profissões que parece não conhecer limites. Ao deixar a sala de aula, o professor não deixa para trás o trabalho e as preocupações com o ensino. Sua casa, seus momentos longe do trabalho se constituem como uma extensão do seu fazer docente (BENTO, 2009).

Destarte, com base no que fora discutido apresentamos os resultados da pesquisa utilizando a análise dos dados obtidos em campo, vale ressaltar que as discussões serão balizadas tomando por base o perfil, formação e trabalho dos professores e, por conseguinte, a prática revelada no ensino fundamental e ensino médio.

\subsection{Perfil, formação e trabalho dos professores sujeitos da pesquisa}

Os sujeitos da pesquisa são todos professores da rede pública estadual da Paraíba. No que se refere ao gênero, 02 deles do sexo feminino e 02 do sexo masculino, a faixa etária dos mesmos varia entre 31 a 45 anos.

É válido ressaltar que, com a finalidade de salvaguardar a identidade dos professores sujeitos da pesquisa, eles serão identificados por meio da letra $\mathrm{P}$ e em sequência a uma numeração de acordo com a modalidade de ensino, a saber: os professores do Ensino Fundamental serão P1 e P2. Já os professores do Ensino Médio serão P3 e P4.

Percebemos quanto à formação acadêmica dos docentes que em sua maioria possui uma pósgraduação na área de educação, apenas um professor revelou não estar cursando. Ainda pensando na formação, de acordo com os professores, vemos a defasagem no que se refere à oferta de cursos de formação continuada por parte da Secretaria Estadual de Educação do estado da Paraíba. Apenas os professores do Ensino Médio participam de formação diante da inserção em um novo programa Escola Cidadã Integral.

Levando em consideração o trabalho do professor, pensamos em dialogar alguns questionamentos: o primeiro levou-se em consideração o exercício de outro tipo de profissão. Os professores P1, P3 e P4 atuam apenas como professores. Por outro lado, P2 revelou trabalhar como autônomo nos finais de semana: "o que eu recebo não supre minhas necessidades". Diante disso, vemos a discussão da valorização profissional, que está amplamente ligado a seu exercício docente.

Outro questionamento foi acerca da carga horária semanal na escola; P1 e P2 lecionam um pouco mais de 20 horas/aulas. Enquanto P3 e P4 atuam 40 horas/aulas, em detrimento da escola as quais lecionam oferecer o ensino integral.

Ainda refletindo sobre o trabalho dos professores indagamos aos mesmos se a escola oferece boas condições de trabalho, e as respostas foram de encontro à falta de materiais necessários, assim como infraestrutura inadequada.

Diante do contexto em que se apresentou a discussão anterior, pensamos na reflexão do seguinte questionamento - Quais as maiores dificuldades encontradas hoje em seu efetivo exercício na instituição? As respostas foram pautadas em dois contextos principais, a saber: a relação escola aluno - família, e a falta de espaços próprios para o ensino da Geografia, como as salas temáticas que 
se revela em outras disciplinas (Matemática, Biologia, Química, Física).

Com isso, é sabido dizer que a prática docente está diretamente relacionada com estes problemas advindos das condições de trabalho e relação com os discentes. Com base nessa premissa é que apresentaremos nos próximos tópicos como foi revelada a prática docente nas escolas campo de pesquisa.

\subsection{A prática revelada nas séries do ensino fundamental}

A fim de se efetivar uma reflexão da prática docente desses professores, foi necessário tanto a observação participante, quanto a coleta de dados por meio de um questionário semiestruturado, portanto, as discussões apresentadas à seguir tomaram por base os questionamentos e respostas obtidas durante a pesquisa. Como pergunta inicial, para sabermos quais as metodologias utilizadas pelos professores nas aulas, indagamos acerca delas, e se estão associadas aos conteúdos. 0 professor P1 utiliza de aulas expositivas, debates, dinâmicas, apresentação de slides e aulas práticas. Enquanto P2 trabalha com aulas expositivas e leitura e interpretação. Ambos os professores associam as metodologias aos conteúdos.

Indo em encontro as metodologias utilizadas pelos professores, procuramos saber quais os recursos são utilizados para a efetivação destas metodologias, e encontramos as seguintes respostas: P1- "Utilizo a televisão, datashow, mapas, cartazes, entre outros, mas, utilizo sempre o Livro Didático"; P2 - "O livro didático, o quadro e revistas para atividades em sala".

Embora P1 esteja sempre procurando trazer novos recursos para a sala de aula, ainda percebemos o uso restrito ao livro didático pelos professores, $\mathrm{P} 2$, por exemplo, utiliza o livro didático em quase todas as aulas, associado à lousa.

Sabemos que para a efetivação da prática pedagógica faz-se necessário um embasamento teóricoprático diante dos conteúdos abordados na Geografia, com isso, indagamos aos professores acerca das dificuldades enfrentadas no desenvolvimento destes conteúdos. 0 que podemos dizer é que P1 apresenta dificuldades na forma de efetivar a aplicação dos conteúdos, e associa o fato com sua formação, o P2 não demostra muitas dificuldades, apenas quando se refere aos fatos históricos abordados pela Geografia.

Buscando saber se os professores utilizam outros espaços para atividades extraclasses, apenas P1 disse que sim, no que se refere às dificuldades para efetivação desta prática, e o que apresentou foi a não contribuição dos alunos, a níveis de comportamento.

Tomando por base as formas de planejamento e avaliação, buscamos responder os seguintes questionamentos: Quais as maiores dificuldades vistas no processo de planejamento das aulas de Geografia? Quão importantes são as formas de avaliação? E quais são empregadas em suas aulas? No que se refere ao planejamento, ambos os professores do ensino fundamental não apresentam dificuldades. P2 aponta a importância das aulas departamentais nesse processo, para ele as discussões que nestas se apresentam contribui bastante para o processo de planejamento. Quanto às formas de avaliação, P1 utiliza avaliação contínua, questionários abertos e simulados e P2 - avaliação contínua e provas.

0 último questionamento baseou-se na possibilidade de articulação da Geografia com as outras disciplinas, os professores P1 e P2 disseram haver a relação na prática em sala, esta com as disciplinas - História, Ciências, Matemática e Arte, mas a articulação entre os professores das disciplinas não é efetivado, há uma grande dificuldade discutida em duas vertentes: a falta de tempo e, por vezes, a falta de iniciativa.

\section{3. $\quad$ A prática revelada nas séries do ensino médio}


Iniciamos as discussões acerca da prática docente, tomando por base as metodologias de ensino utilizadas e se estes estão associados aos conteúdos. Tivemos uma diversidade de respostas tanto por P3, quanto por P4, vejamos: P3 - "Além da aula expositiva, trabalhamos com exibição, discussão e análise de vídeos e música, leitura e discussão de textos e imagens, pesquisas e exercícios, estes sempre relacionados com os conteúdos". P4 - "aulas dialogadas, discursivas e aulas práticas".

Estas metodologias utilizadas pelos professores P3 e P4, condizem com as mais tradicionais, entretanto, já se apresenta com uma diversidade, como aponta o professor P3. A proposta de aula de modo inovador é algo muito importante, está intrinsecamente relacionado à aprendizagem dos alunos e à boa prática docente. Com base nestas concepções, compreendemos que o professor P3 exerce uma prática eficaz no que se refere às metodologias utilizadas. A professora $\mathrm{P} 4$, ainda faz-nos dialogar com a aula ligada à exposição e discussão.

Para sabermos como se dá a efetivação destas metodologias, buscamos compreender quais os recursos são utilizados, e se os professores consideram inovador. 0 professor P3 diz ser inovador através da utilização de vários recursos audiovisuais presentes nas TICcomo o kit multimídia, TV, música, imagens e mapas digitais, globo e pesquisas impressas. P4 está sempre associando à sua prática ao uso de recursos audiovisuais, mapas, globos e principalmente o livro didático. Contudo, é importante dizer que os recursos utilizados pelos professores mesmo sendo de cunho inovador, mas, depende diretamente da metodologia e efetivação de seu uso. Destacando também a grande variedade de recursos que a escola do ensino médio dispõe.

Ao indagar quais as dificuldades apresentadas no desenvolvimento dos conteúdos, os professores P3 e P4 apontam uma diversidade de problemas, para melhor entender, destaco: P3 - "A maior dificuldade está em associar os conteúdos com a realidade dos educandos, interligando as questões local e global; As maiores dificuldades encontram-se nos conteúdos relacionados à Geografia Física" e P4 - "Na atualidade as dificuldades estão relacionadas à maneira como são conduzidas as didáticas e metodologias utilizadas na geo-escolar. Além do problema da indisciplina e ausência da família".

Por conseguinte, discutimos acerca da interferência da formação acadêmica à sua prática, e as respostas foram positivas dos dois professores (P3 e P4), como vemos: P3 -“Ao ingressar na vida docente passamos a utilizar técnicas e práticas de ensino dentro de uma proposta atrativa e inovadora observada durante a formação". Enquanto P4 - "A formação me deu instrumentação para trabalhar os conteúdos de forma pedagógica e geográfica". Ou seja, diante do exposto recorremos à premissa de que as formações destes professores estão ligadas diretamente à sua prática de ensino.

Buscando entender se as práticas transcendem as salas de aula, propomos dois questionamentos - se são utilizadas práticas em outros espaços e quais as dificuldades para a realização de tal. Ambos os professores do ensino médio responderam que sim, entretanto, apontam a dificuldade presente, e resumem em apenas uma: o deslocamento dos estudantes até o local, o transporte. Este problema é geral, a secretaria estadual na gerência do município conta com um número reduzido de ônibus escolares, ou estão em uso contínuo, ou está quebrado, assim, dificulta a realização destas atividades. Apesar disso, o professor P3 realiza estudos do meio nos ambientes internos e externos à estrutura da escola, para que as aulas não sejam restritas à sala.

Com base nestes apontamentos sabemos da importância do planejar, na busca de conduzir melhor as aulas. Contudo, entendemos que alguns professores apresentam dificuldades relacionadas a tal, todavia, incluímos à análise, quais as maiores dificuldades vistas no processo de planejamento das aulas de Geografia, e a preocupação central é justamente a de desenvolver metodologias que tornem as aulas mais atrativas e significativas, para estes professores, o grande desafio é trazer o olhar do aluno para a reflexão, o que está sendo difícil de efetivar.

Entretanto, vale destacar também como se dá as formas de avaliação da disciplina Geografia nas aulas destes professores, assim como a importância destas. P3 destaca que "a avaliação tem papel 
fundamental no planejamento das aulas e desenvolvimento de novas metodologias, normalmente são realizadas de forma contínua, sendo mais qualitativa que quantitativa"; já o professor P4 diz que sua forma de avaliar é pautada em participações, arguições e seminários. Baseando-se nesta ideia diante da coleta dos dados e das conversas em atuação nas escolas, elencamos que o professor P3 visa sempre avaliar continuamente, com base nas qualidades, enquanto o professor P4 aborda as notas como forma de avaliação, ou seja, dados mais quantitativos.

Como enfoque conclusivo de questionamento, procuramos saber ainda se há a articulação das aulas de Geografia com outras disciplinas, e de qual forma. Destacamos esse processo interdisciplinar pautado em duas discussões, P3 diz que essa prática não é muito efetivada, mas, espera que a realidade de articulação alcance outro patamar com a Escola Cidadã. 0 professor P4 diz que há essa relação, levando em consideração os projetos de intervenção pedagógica através dos temas transversais. Assim, pensamos a importância da Geografia enquanto uma disciplina capaz de se interligar com as demais, e está sempre utilizada nas discussões voltadas aos temas transversais. Este ano por exemplo, tomando por base o eixo Meio Ambiente, a Geografia tem papel fundamental, aponta o professor P4.

\section{Considerações Finais}

Discutir acerca da prática de ensino em Geografia foi algo que emergiu diante da atuação no âmbito educacional, muito embora de forma tardia. Entretanto, em meio a estas discussões foi possível perceber o quão prazeroso é conhecer como os processos de ensino-aprendizagem se revelam. A cada dia nas escolas, a cada contato com os professores de Geografia e os alunos destes pudemos perceber a necessidade de uma reflexão acerca da prática docente. Diante dos encontros, pudemos perceber as grandes dificuldades que permeiam o ensino público em um âmbito local, o que não se distancia de uma realidade distante. Assim como, o quanto essas dificuldades interferem na construção do conhecimento.

Diante do diagnóstico através da pesquisa documental, vimos que as escolas onde a pesquisa se efetivou, apresentam problemas diversos, os quais dois destes foram vistos com maior incidência, a saber: a falta de recursos e de espaços. Com relação aos que as compõe, o que se percebe é a indignação dos professores no que se refere ao comportamento dos alunos e a não efetivação do contato com os pais, o que torna como sendo um grande problema.

Com base na formação dos professores, vimos que os estes possuem graduação em Geografia e a maioria é especialista na área. Alguns deles não participam há anos de formação continuada, este fator ligado à falta de tempo. Assim, revelando a ocupação em outros horários a não ser quando leciona nestas escolas, fator este justificado diante da não valorização profissional.

No que se refere ao trabalho docente, ficou perceptível que a carga horária é normal, mas, demonstra a precariedade quanto às condições de trabalho, principalmente, através da ausência de recursos, muitas vezes sendo passível o improviso para a sistematização dos conteúdos em sala de aula.

A prática em si, foi revelada diante da utilização de metodologias de ensino, de maneira defasada, sendo o recurso utilizado de forma restrita para a efetivação das aulas, o livro didático. Embora, alguns professores busquem utilizar de outras metodologias, mas, não é algo contínuo, só acontece quando o professor dispõe de tempo, e consegue enfrentar os problemas perpassados.

Com base no que mostramos, podemos dizer que a prática de ensino dos professores de ItabaianaPB, se revelou como estando passível de uma reflexão. Partindo como premissa do próprio professor, na tentativa de superar os obstáculos vivenciados e introduzir métodos capazes de suprir as necessidades. Se cada professor revir sua prática, possivelmente emergirão propostas de intervenção nessa realidade em que se configura o ensino público.

Deste modo, com base nos grandes problemas perpassados, bem vistos diante dos encontros, 
pensamos que através de ações na escola, os professores pudessem pensar sua prática e perceber o quão importante é o uso de metodologias inovadoras no processo de ensino-aprendizagem. Destarte, esta atividade prática, que revela a ação da pesquisa está apresentada em outro trabalho, intitulado OFICINAS PEDAGÓGICAS COMO APORTE TEÓRICO-METODOLÓGICO NO PROCESSO DO ENSINARAPRENDER GEOGRAFIA, publicado no Encontro nacional de Prática de Ensino de Geografia - ENPEG, Belo Horizonte, 2017.

\section{Referências}

BENTO, Izabella Peracini. Saberes e práticas de professores de geografia referentes ao conteúdo cidade no cotidiano escolar. 2009. Dissertação (Mestrado em Geografia) - Universidade Federal de Goiás, Goiânia, 2009.

CAVALCANTI, Lana de Souza. Geografia, escola e construção de conhecimentos. 4. ed. Campinas: Papirus, 2003.

TARDIF, Maurice. Saberes docentes e formação profissional. 16. ed. Petrópolis, RJ: Vozes, 2014. 